Kansas State University Libraries

New Prairie Press

\title{
EVALUATING LINEAR AND NONLINEAR MODELS FOR THE RESPIRATION RATE OF FOUR BREEDS OF HEAT STRESSED FEEDLOT HEIFERS
}

Q. Huang

A. M. Parkhurst

T. M. Brown-Brandl

R. A. Eigenberg

J. A. Nienaber

See next page for additional authors

Follow this and additional works at: https://newprairiepress.org/agstatconference

Part of the Agriculture Commons, and the Applied Statistics Commons (c) (1) $(9)$

This work is licensed under a Creative Commons Attribution-Noncommercial-No Derivative Works 4.0 License.

\section{Recommended Citation}

Huang, Q.; Parkhurst, A. M.; Brown-Brandl, T. M.; Eigenberg, R. A.; and Nienaber, J. A. (2006). "EVALUATING LINEAR AND NONLINEAR MODELS FOR THE RESPIRATION RATE OF FOUR BREEDS OF HEAT STRESSED FEEDLOT HEIFERS," Conference on Applied Statistics in Agriculture. https://doi.org/10.4148/ 2475-7772.1129

This is brought to you for free and open access by the Conferences at New Prairie Press. It has been accepted for inclusion in Conference on Applied Statistics in Agriculture by an authorized administrator of New Prairie Press. For more information, please contact cads@k-state.edu. 
Author Information

Q. Huang, A. M. Parkhurst, T. M. Brown-Brandl, R. A. Eigenberg, and J. A. Nienaber 


\title{
EVALUATING LINEAR AND NONLINEAR MODELS FOR THE RESPIRATION RATE OF FOUR BREEDS OF HEAT STRESSED FEEDLOT HEIFERS
}

\author{
Q. Huang ${ }^{1}$, A. M. Parkhurst ${ }^{1}$, T.M. Brown-Brandl ${ }^{2}$, R.A. Eigenberg ${ }^{2}$, and J.A. Nienaber ${ }^{2}$ \\ 1. Department of Statistics, University of Nebraska at Lincoln \\ 2. U.S. Meat Animal Research Center
}

\begin{abstract}
Heat stress is a factor that causes loss of production and even death in cattle. Animals differ in vulnerability to heat stress. One reason for the difference may be the coat color associated with different breeds or genotypes. A good measure of the heat stress is respiration rate which increases in response to increasing ambient temperature. The objective of this study is to characterize the respiration rates of four genotypes of heat stressed feedlot heifers. Linear and nonlinear models will be compared to find an appropriate method of detecting differences among genotypes.
\end{abstract}

\section{INTRODUCTION}

Heat stress in cattle has a negative impact on animal performance and well-being. Frequently, losses in production are reported due to decreases in feed intake, growth and efficiency (Hahn, 1999). In extreme cases, heat stress can even result in death of vulnerable animals (Hahn and Mader, 1997). Coat color is one characteristic of vulnerable animals (Busby and Loy, 1996; Hungerford et al., 2000; Mader et al., 2001). The coat color associated with different breeds or genotypes may be one of the factors that causes differences in response to heat stress. Animals with dark hides are thought to be more vulnerable than light-hided animals due to the adsorption of solar radiation. In a study by da Silva et al. (2003), adsorption of solar radiation from a blackhided animal was $93 \%$, while a light-hided animal was only $27 \%$. Another characteristic of vulnerability to heat stress is the availability of shade. Busby and Loy (1996) reported results of a producer's survey taken to identify factors contributed by a 1995 heat wave in western Iowa. They found that producers with non-shaded lots had the highest death loss in dark-hided animals.

Respiration rate (RR) has been shown to be a good indicator of thermal stress (Brown-Brandl et al., 2002; Gaughan et al., 2000; Hahn et al., 1997). Several authors (Eigenberg et al., 2002; Hahn et al., 1997) have shown respiration rate increases in a non-linear fashion in response to increasing ambient temperature (Ta). One advantage of using respiration rate as an indication of stress is that it is readily observable in a production setting (Hahn et al., 1997).

In this study, we will attempt to characterize the non-linear relationship between RR and Ta by a quadratic regression and an exponential regression model. The quadratic regression is an empirical model that is linear in its parameters. We will examine the fixed effects and mixed model versions of this linear model. Similarly, we will examine fixed and mixed model versions of the nonlinear exponential model. We will also recommend a model that can address the question of whether or not dark-hided heifers become more heat stressed than light-hided ones; that is, does RR increase more rapidly for dark-hided heifers than for light-colored heifers during periods of heat stress? To strengthen our recommendation, after fitting the fixed and mixed 
model versions of the quadratic and exponential, we will repeat the process incorporating the experiment treatment factor of genotype and shade.

\section{MATERIALS AND METHODS}

\section{2.a Experimental Design}

A study of four genotypes of heifers, Angus (A), Charolais (C), Gelbvieh(G), and MARC III crossbred (M), was conducted over two consecutive summers (2002 - 2003) in the USDA-ARSMARC feedlot. The Angus heifers were all solid black. The Charolais heifers were solid white. The MARC III crossbred heifers were mostly dark red (three of 64 were black; some were solid, while others had white tailheads and/or white faces). The Gelbvieh heifers were solid tan. The feedlot was a block of four adjacent pens. Shade was available in half of each pen. Each year heifers were assigned to one section of the eight pen-sections by genotype (16 heifers/pen-section). These arrangements resulted in a single level hierarchical design. Sixteen heifers of the same genotype are nested

\begin{tabular}{|c|c|c|c|c|}
\hline Pen & 1 & 2 & 3 & 4 \\
\hline Environment.......... & A & M & G & C \\
\hline Shade & M & C & A & G \\
\hline No Shade & M
\end{tabular}
in one of the 8 pen-sections. Hence, the experiment treatment factor (shade-genotype) is unreplicated and is confounded with pen-section. Only data from the first summer (2002) was used in this study.

Measurements of RR were made twice daily (0800 and 1430) on ten heifers per genotype during six 5-day periods between June 24 and August 9 in 2002. On scheduled experimental days, two observers worked independently. Each randomly selected five animals per pen and recorded RR, by visual observation of flank movement, timing 10 breaths with a stopwatch. The average Ta was calculated based on weather data recorded prior to and immediately after animal observations.

\section{2.b Statistical Models}

When choosing a regression model to characterize how the RR response (Y) varies with Ta (X), we have the option of choosing a polynomial which is linear in its parameters. The quadratic polynomial we choose is an empirical model, devoid of theoretical assumptions, based only on the data. The physical meaning of the parameters is irrelevant. We also choose a mechanistic model which is based on theoretical considerations. These considerations endow the parameters with a natural physical interpretation. The nonlinear exponential regression is derived from a differential equation which is based on the assumption that the rate of change in RR is proportional to the current $\mathrm{RR}$, i.e., $\partial \mathrm{Y} / \partial \mathrm{X}=k a p p a^{*} \mathrm{Y}$. For the resulting exponential regression, $\mathrm{y}=$ alpha $* \mathrm{e}^{-k a p p a * \mathrm{X}}$, the parameter alpha is the respiration rate when Ta is $0^{\circ} \mathrm{C}\left(32^{\circ} \mathrm{F}\right)$, and kappa is the rate constant in units of reciprocal Ta. Other issues to consider when using nonlinear models are the intrinsic and parameter-effects nonlinearity (Bates and Watts, 1988). Preliminary analyses to check for nonlinear behavior showed the percent excess variance for all parameters was greater than $1 \%$. Thus, we re-parameterized the model using $\log ($ alpha $)=$ beta . The exponential model $y=\mathrm{e}^{\text {beta-kappa }{ }^{*} x}$ passed the checks for parameter-effects nonlinearity. In fact, this parameterization is described by Ratkowsky (1990) as having close-to-linear behavior and is called the exponential offset regression, with beta being referred to as the offset. Note: 
Another parameterization with poorer close-to-linear behavior but with an interesting interpretation is obtained if we let beta=tau/kappa. In this case, tau is the lag in Ta, that is, the setback in Ta to reach $0 \mathrm{C}$.

Since animal studies are notable for substantial variability in animals, we group the observations by heifer and employ mixed model methods to incorporate both fixed-effects terms and randomeffects terms. The fixed-effects terms describe the behavior of the entire population of heifers in a pen-section. The random-effects terms describe the behavior of the individual heifers in the pen-section. Thus, we use the linear mixed models to fit the quadratic regression to the data and the nonlinear mixed model to fit the exponential regression. The analyses were preformed in $\mathrm{R}$, a free software environment for statistical computing and graphics. The linear and nonlinear mixed models were fit using the lme and nlme functions, respectively, in the nlme library in version 2-1.1 of R. Additional powerful diagnostic graphics come from the trellis library.

\section{2.b.i Linear Mixed Model: Quadratic Regression}

The following linear mixed effects covariance model was considered.

$$
\begin{aligned}
& \mathbf{Y}_{\mathbf{i}}=\text { betaI }+ \text { betaL }^{*} \mathbf{X}_{\mathbf{i}}+\text { beta } Q * \mathbf{X}^{2}+\boldsymbol{\varepsilon}_{\mathbf{i}} \quad \mathbf{i}=1, \ldots, 8 \\
& \text { where } \boldsymbol{\varepsilon}_{\mathbf{i}} \sim \mathrm{N}\left(0, \mathbf{I} \boldsymbol{\sigma}^{2}\right) \text {, } \\
& \text { betaI }=\boldsymbol{\beta}_{10}+\boldsymbol{\beta}_{11} \cdot \boldsymbol{C}_{1}+\boldsymbol{\beta}_{12} \cdot \boldsymbol{C}_{2}+\cdots+\boldsymbol{\beta}_{17} \cdot \boldsymbol{C}_{7}+\boldsymbol{b}_{\mathrm{i}, 0} \\
& \operatorname{betaL}=\boldsymbol{\beta}_{20}+\boldsymbol{\beta}_{21} \cdot \boldsymbol{C}_{1}+\boldsymbol{\beta}_{22} \cdot \boldsymbol{C}_{2}+\cdots+\boldsymbol{\beta}_{27} \cdot \boldsymbol{C}_{7}+\boldsymbol{b}_{\mathrm{i}, \mathrm{Ta}} \\
& \operatorname{beta} \boldsymbol{Q}=\boldsymbol{\beta}_{30}+\boldsymbol{\beta}_{31} \cdot \boldsymbol{C}_{1}+\boldsymbol{\beta}_{32} \cdot \boldsymbol{C}_{2}+\cdots+\boldsymbol{\beta}_{37} \cdot \boldsymbol{C}_{7}+\boldsymbol{b}_{\mathrm{i}, \mathrm{Ta}}^{2} \\
& \boldsymbol{b}_{\mathrm{i}}=\left(\begin{array}{l}
b_{\mathrm{i}, 0} \\
b_{\mathrm{i}}, \mathrm{Ta} \\
b_{\mathrm{i}, \mathrm{Ta}}^{2}
\end{array}\right) \sim \mathrm{N}(0, \Psi) \text {, where } \Psi=\left(\begin{array}{ccc}
\boldsymbol{\sigma}_{0}^{2} & \boldsymbol{\sigma}_{0 \mathrm{Ta}} & \boldsymbol{\sigma}_{0 \mathrm{Ta}}{ }^{2} \\
\boldsymbol{\sigma}_{\mathrm{Ta} 0} & \boldsymbol{\sigma}_{\mathrm{Ta}}^{2} & \boldsymbol{\sigma}_{\mathrm{Ta} \mathrm{Ta}}^{2} \\
\boldsymbol{\sigma}_{\mathrm{Ta}^{2} 0} & \boldsymbol{\sigma}_{\mathrm{Ta}}{ }^{2} \mathrm{Ta} & \boldsymbol{\sigma}_{\mathrm{Ta}}^{2}
\end{array}\right)
\end{aligned}
$$

The $C_{1}, C_{2}, \ldots, C_{7}$ are dummy variables defined to incorporate the shade-genotype effects. Both the fixed and random effects were considered for betaI, betaL and betaQ, the regression coefficients for a second-order polynomial regression of $\mathrm{RR}$, the response variable $(y)$, on Ta, the covariate $(x)$. The meaning of the fixed-effect coefficients is as follows: $\beta_{10}, \beta_{20}$ and $\beta_{30}$ are the means of the first shade-genotype treatment for betaI, betaL and beta $Q$ respectively; $\beta_{11}, \beta_{21}$ and $\beta_{31}$ are the differences of the means between the second and first shade-genotype treatment for betaI, betaL and beta $Q$ respectively; and similarly up to the eighth shade-genotype treatment level. The random effects $b_{i, 0}$ represent the deviation from the population mean associated with the $\mathrm{i}^{\text {th }}$ pen and betaI, similarly for the linear, and quadratic regression coefficients. The $b_{\mathrm{i}}$ ' $\mathrm{S}$ and $\varepsilon_{i}$ are assumed independent of each other. 


\section{2.b.ii Nonlinear Mixed Model: Exponential Regression}

When respiration was assumed to increase at an exponential rate, the following nonlinear mix model was considered.

$$
\begin{array}{rl}
\mathbf{Y}_{\mathbf{i}}=\boldsymbol{b e t a}^{*} \mathbf{e}^{- \text {kappa }^{*} \mathbf{X}_{\mathbf{i}}+\varepsilon_{\mathrm{i}}} & \mathrm{i}=1, \ldots, 8 \\
\text { where } \boldsymbol{\varepsilon}_{\mathbf{i}} \sim \mathrm{N}\left(0, \mathbf{I} \boldsymbol{\sigma}^{2}\right), & \\
\text { beta } & =\boldsymbol{\beta}_{10}+\boldsymbol{\beta}_{11} \cdot \boldsymbol{C}_{1}+\boldsymbol{\beta}_{12} \cdot \boldsymbol{C}_{2}+\cdots+\boldsymbol{\beta}_{17} \cdot \boldsymbol{C}_{7}+\boldsymbol{b}_{\mathrm{i}, \mathrm{beta}} \\
\boldsymbol{k a p p a} \boldsymbol{a} & =\boldsymbol{\beta}_{20}+\boldsymbol{\beta}_{21} \cdot \boldsymbol{C}_{1}+\boldsymbol{\beta}_{22} \cdot \boldsymbol{C}_{2}+\cdots+\boldsymbol{\beta}_{27} \cdot \boldsymbol{C}_{7}+\boldsymbol{b}_{\mathrm{i}, \mathrm{kappa}}
\end{array}
$$

$$
\boldsymbol{b}_{\mathrm{i}}=\left(\begin{array}{l}
\boldsymbol{b}_{\text {i,beta }} \\
\boldsymbol{b}_{\text {i,kappa }}
\end{array}\right) \sim \mathrm{N}(0, \Psi), \quad \text { where } \Psi=\left(\begin{array}{cc}
\boldsymbol{\sigma}_{\text {beta }}^{2} & \boldsymbol{\sigma}_{\text {beta kappa }} \\
\boldsymbol{\sigma}_{\text {kappa beta }} & \boldsymbol{\sigma}_{\text {kappa }}{ }^{2}
\end{array}\right)
$$

The $C_{1}, C_{2}, \ldots, C_{7}$ are dummy variables defined to incorporate the shade-genotype effects. Both the fixed and random effects were considered for beta and kappa. The meaning of the fixedeffect coefficients is as follows: $\beta_{10}$ and $\beta_{20}$ are the means of the first shade-genotype treatment for beta and kappa respectively; $\beta_{11}$, and $\beta_{21}$ are the differences of the means between the second and first shade-genotype treatment for beta and kappa respectively; and similarly up to the eight shade-genotype treatment levels. The random effects $b_{\mathrm{i} \text {, beta }}$ represents the deviation from the population mean associated with the $\mathrm{i}^{\text {th }}$ pen and beta. The $b_{\mathrm{i}}$ 's and $\varepsilon$ are assumed independent of each other.

\section{RESULTS AND DISCUSSION}

\section{3. a. Relationship between Respiration Rate and Dry-bulb Temperature}

A popular approach to modeling the relationship between $\mathrm{RR}$ and $\mathrm{Ta}$ is to fit a linear fixedeffects model to the entire data set (Figure 1 and Table 1). If the primary focus is on the effects of genotype, it is tempting to fit a separate linear regression for each genotype, Figure 2. A slightly more sophisticated approach is to perform an analysis of covariance which incorporates the genotype treatment effects (ignoring availability of shade) with the covariate Ta. The inclusion of genotype effect (model not shown) significantly reduces the residual standard deviation of the linear fixed-effect model $(p<0.0001)$ from 26.02 to 24.26 . None of these approaches take into account the curvature in the data.

In an attempt to capture the curvature, two regression fixed-effects models, quadratic and exponential, were fit to the data. The coefficients and residual standard error are given in Table 1 . Both models have statistically significant parameter estimates (alpha $=0.05$ ). Thus, both models support the assumption of curvature.

\section{3.b Linear Model: Quadratic Regression}

\section{3.b.i Linear Fixed Model: Quadratic Regression}

When we compare the quadratic and linear regression fixed models, discussed above, we see the residual standard error is reduced as we add the quadratic term. The F-ratio for reduction in sum of squares is significant, $\mathrm{p}=0.0002961$, indicating the quadratic effect makes a contribution to 
fitting this data. When the experiment shade-genotype treatment factor is included in the model, all the regression coefficients are significant (not shown). Once again, we compare the quadratic and linear regression fixed model, this time including the treatment factor. For the fixed case including treatments, the quadratic is superior to the linear (model not shown). The reduction sum of squares F-ratio is significant $(\mathrm{p}=0.001091)$ and residual standard error is reduced from 24.46 to 23.76 for the linear and quadratic, respectively.

Recall the primary motivation for this study is to see if there are differences in how genotypes react to heat challenges (increases in Ta). We begin by including the shade and genotype treatment factor in the fixed-effects model. Results for the quadratic linear fixed-effects model are listed in Table 2 Model 6. We compare these results to those for model 1 (quadratic fixed effect model without treatment, discussed above) using the SS-reduction F-test. We find inclusion of the treatment effects significantly reduces the residual error $(p=0.0006)$.

\section{3.b.ii Linear Mixed Model: Quadratic - Ignoring Experiment Treatment Factors}

For the mixed models, we consider four random-effects structures: intercept, linear Ta, quadratic $\mathrm{Ta}$, and the diagonal (intercept, $\mathrm{Ta}, \mathrm{Ta}^{2}$ ) which assumes the random-effects are independent. The residual standard error, information criteria and log-likelihood are provided in Table 2-Models 25 , respectively. To establish the importance of including random effects in the model, the fixedeffects for mixed model 2 (quadratic regression with random intercept), are reported in Table 1 and compared to those for model 1 (quadratic regression: fixed effect model without treatment). The standard errors are smaller for all estimates. The likelihood ratio constructed from Table 2 (Models $1 \& 2)$, is significant $(\mathrm{p}<0.0001)$. Thus, the inclusion of random-effects significantly improves the fit.

To identify which random effects to incorporate in the model and what their covariance structure should be, we use the results from 127 heifer individual regressions. We examine the 95\% confidence intervals for each heifer, Figure 3 Quadratic, to see how the parameter estimates vary among heifers. While it is clear that random effects are needed to account for heifer to heifer variability, the parameter estimates appear to be highly correlated. The scatter plot of the correlation among the random effects, Figure 4, suggests the need for a covariance structure.

Plots of the individual and mixed model (3) fixed-effect estimates are displayed in Figure 5. The mixed model estimates are frequently called "shrinkage estimates" (Pinheiro and Bates, 2000) because they are "pulled toward" the individual estimates. They represent a compromise between the individual fits and the fixed-effects of the mixed model which are associated with the population average. Again we see substantial variation across heifers.

The random-effects of the four mixed models (2- 5) are reported in Table 3. There appears to be little variability associated with $\mathrm{Ta}^{2}$, while there is a strong relationship between the intercept and Ta. In fact, comparing these models using the information criteria and likelihood ratio tests we find model 3 (linear random-effects structure) provides the best fit. We assess the quality of this fit by examining plots of the predicted values from the linear mixed model with the predicted values from the individual heifer regressions. A subset of these plots for 24 heifers is given in 
Figure 6 Quadratic. Model 3 does appear to account for variability among heifers; but, it fails to capture the full extend of the curvature in the data.

\section{3.b.iii Linear Mixed Model: Quadratic Including Experiment Treatment Factors} For the mixed model with treatment factor, the four random-effects structures described above are fit to the data. The information criteria and log likelihood for these models are listed in Table 2 (Models 7-10). The random effects estimates are given in Table 3. Comparing randomeffects estimates to those from models without the treatment factor (models 2-5), we see the quadratic effect, $\mathrm{Ta}^{2}$, becomes even smaller and the correlation between intercept and $\mathrm{Ta}$ is reduced, although it is still ample. Comparing the models with the treatment factor (models 710) using the information criteria and likelihood ratio tests, we find model 8 (linear random effects) provides the best fit. The random-effects structure did not change when the treatment factor was included.

Examination of the random-effects produced by model 8, Figure 7 Quadratic, shade is an important factor. Heifers without access to shade have a different pattern then those that do have shade available.

Next we examine the within-group (i.e. heifer) residuals. From the box-plots in Figure 8, we see the standardized residuals are centered at zero but there is large within-group variance, that is, variability changes with animal. A few of the intervals do not cover zero and several have an outlying observation. Treatment factor plots of the residuals versus fitted (or predicted) values, Figure 9 Quadratic, show only Charolais with/without shade and Gelbvieh-without shade are free of outliers. Variability in RR differs by both genotype and shade. The assumption of normality for the within-group residuals can be assessed with normal probability plots, Figure 10. The tails are heavier than expected under normality. But, the picture changes when viewed by treatment factors, Figure 11 Quadratic. Although there are outliers, the deviations from normality do not appear so worrisome.

\section{3.c.i Nonlinear Fixed Model: Exponential Regression}

The fixed nonlinear exponential regression is another model that captures the curvature in the data, Table1. The information criteria and log-likelihood are reported in Table 2 (Model 11). When the data are grouped by heifer, 127 individual regressions can be fit. The estimated within-group standard error 25.98 is slightly larger than the residual standard error in the individual regressions, 22.47. Plots of the individual heifer confidence intervals for beta and kappa, Figure 3 Exponential, indicate substantial variation among heifers; and, even though the parameter estimates are highly correlated (0.98), we elect to keep both parameters in the model and proceed to fit the nonlinear mixed-effects version of the exponential model.

\section{3.c.ii Nonlinear Mixed Model: Exponential Ignoring Experiment Treatment Factors}

We consider three mixed models; one with a random effect for beta, another with a random effect for kappa and another with random effects for both parameters. All three models indicate a very high correlation $(\sim 0.92)$ between fixed effects, beta and kappa. The residual standard error, 
information criteria and log likelihood are provided in Table 2 (Models $12-14$ ), respectively. The mixed models offer significant improvement over the fixed model 11; the p-values for the likelihood ratio test were all less than 0.0001 . The estimates of the random effects for the three models are given in Table 4 . The low correlation (0.368) between random effects, beta and kappa suggests we may not need both parameters in the random-effects structure to fit this data. If we restrict our attention to a single random effect, beta is by far the largest. The likelihood ratio test indicates that the model with two parameters (model 14) improves the fit compared to the model with one random-effect if that effect is kappa $(\mathrm{p}<0.000)$; but it offers no significant improvement over using beta alone $(\mathrm{p}=0.1624)$. Using the principle of parsimony, we conclude model 12, the nonlinear mixed exponential regression with random effect beta is the best choice to fit the data ignoring the experiment treatment factor.

An assessment of the quality of the fitted model is provided by the plot of the augmented predictions, Figure 6 Exponential. The fitted values, representing the average of the heifer population, track the curvature over the observed Ta range. Also, the individual heifer predictions are in good agreement with the observed variability in RR.

\section{3.c.iii Nonlinear Mixed Model: Exponential Including Experiment Treatment Factors} Using the same three mixed models with the treatment factor further reduces the residual standard error, Table 2-Models 15 - 17. The question is which random effects are important. A plot of the random effects for both parameters by shade and genotype, Figure 7 Exponential, indicates the random effects parameters are correlated. The random effect estimates are given in Table 4. The standard deviation for kappa-alone (model 16) is reduced to 0.00323 and the correlation between beta and kappa (model 17) is increased to 0.884 . The reduction in kappa implies part of the heifer-to-heifer variation may be explained by the treatment factor. The increase in the correlation between beta and kappa suggests the random effects may be overparameterized. To test these implications, we check the information criteria and likelihood ratios. The likelihood test shows two parameters (model 17) are better than kappa alone (model 16), $\mathrm{p}<0.0001$, but, that may be because beta is one of the random effects. The two parameter structure (model 17) offers no significant improvement to using beta alone (model 15), $\mathrm{p}=0.2042$. Once again, the principle of parsimony is invoked. We conclude that model 15 offers a good fit to the data. The same random effects structure is chosen whether we include or ignore the treatment factors.

Model diagnostics were performed by examining the plot of the standardized residual versus the fitted values by shade and genotype, Figure 9 Exponential. The residuals are distributed symmetrically around zero, with roughly uniform variance. Only Charolais-with/without shade and Gelbvieh-without shade are free of outliers. The normal plot of the within-group residuals by shade and genotype, Figure 11 Exponential, supports the assumption of normality.

\section{3.d Comparing Quadratic and Exponential Regressions}

Practical differences favor the quadratic. It is easier to fit and understand. The exponential requires good starting values for convergence and that can be a difficult task; but, the payoff is the parameters have a natural physical interpretation; beta is the offset and kappa is the rate 
constant. In other respects, the regressions are similar. Both the quadratic and exponential use data grouped by heifer to describe RR as a function of Ta taking into account the correlation among observations for a heifer. Both the quadratic and exponential provide for curvature in the relationship between RR and Ta. For this data, both needed significant random-effects structures to represent within-heifer dependence and both affirmed the validity of assumptions on the random-effects and residual error. The main difference is in the quality of fit as assessed by Figure 6 Quadratic and Exponential. The nonlinear exponential model appears to be far superior to the quadratic regression.

\section{CONCLUSIONS}

Descriptions of the relationship between RR and Ta improve when curvature is built-into the model. Since curvature is a prominent feature of both the quadratic and exponential regressions, they showed improvement when compared to the linear regression.

Variability in RR differs by both genotype and shade. Each regression shows considerable improvement when the shade-genotype treatment factor is incorporated into the model, attesting to the presence of shade-genotype effects. Future studies conducted using a 2-way factorial treatment design with replication would allow us to examine the interaction of shade and genotype.

Both regressions also show improvement when random effects are used to account for the random variation in heifers attesting to the usefulness of mixed models. The plots of the augmented predictions provide a way to assess the quality of fit and a way to compare mixed models. For this data, the exponential regression is the model of choice. It is clearly superior to the quadratic regression both in terms of quality of fit and insightfulness of interpretation.

\section{SUMMARY}

In an attempt to characterize heat stress in four breeds of heifers, respiration rate, RR, was measured twice daily and recorded along with the computed ambient temperature. The data was gathered from a single level hierarchical design conducted in the USDA-ARS-MARC feedlot. Each of four pens was sectioned into shade and no shade areas. Sixteen heifers from each of four genotypes, two dark-hided (Angus and MARC-III) and two light-colored (Charolais and Gelbvieh) heifers were assigned to one of the eight pen-sections. The shade-genotype treatment factor was un-replicated and confounded with the pen-section. A linear mixed model analysis was performed for a quadratic regression; while, a nonlinear mixed model analysis was performed for the two-parameter exponential regression, $\mathrm{RR}=\exp$ (beta-kappa*Ta). Both regressions verified the assumption of curvature in the RR-Ta relationship. Both mixed model regressions showed improvement over their fixed model counterpart and they both improved when the experimental shade-genotype treatment factor was included in the analysis. The best fit for the quadratic came from a mixed model with a linear Ta random-effects structure. The best fit for the exponential came from a mixed model with singe random-effect on beta. Plots of the augmented predictions show the exponential regression is far superior. The parameters of that model have a natural interpretation useful for comparing levels of the experiment treatment factor with beta being the offset constant and kappa, the RR rate constant. Thus, when 
investigating shade and genotype effects under the conditions of the motivating experiment, we recommend using the nonlinear exponential mixed model with random-effect beta, to analyze the data.

\section{REFERENCES}

Bates, D.M. and D.G. Watts, 1988. Nonlinear Regression Analysis and its Applications. NewYork: John Wiley.

Brown-Brandl, T.M., Eigenberg, R.A., Hahn, G.L., Nienaber, J.A., Mader, T.L., Spiers, D.E., Parkhurst, A.M., 2002. Dynamic responses of feeder cattle to simulated heat waves. Paper No. 024051. St. Joseph, Mich: ASAE.

Busby, D., Loy, D., 1996. Heat stress in feedlot cattle: Producer Survey Results. Beef Research Report. A.S. Leaflet R1348. Ames, IA, Iowa State University.

da Silva, R.G., La Scala, N. Jr., Tonhati, H., 2003. Radiative properties of the skin and haircoat of cattle and other animals. Trans. ASAE 46, 913-918.

Eigenberg, R.A., Brown-Brandl, T.M., Nienaber, J.A., Hahn, G.L., 2002. Dynamic response of feedlot cattle to shade and no-shade. Paper No. 024050. St. Joseph, Mich: ASAE.

Gaughan, J.B., Holt, S.M., Hahn, G.L., Mader, T.L., Eigenberg, R.A., 2000. Respiration Rate - Is it a good measure of heat stress in cattle? J. Anim. Sci. 13, 329-332.

Hahn, G.L., 1999. Dynamic responses of cattle to thermal heat loads. J. Anim. Sci. 77, 10-20.

Hahn, G.L., Mader, T.L., 1997. Heat waves in relation to thermoregulation, feeding behavior and mortality of feedlot cattle. Proc. 5th Int. Livestock Environment Symposium, Vol I, 563-571. SP01-97, St. Joseph, Mich: ASAE.

Hahn, G.L., Parkhurst, A.M., Gaughan, J.B., 1997. Cattle respiration rate as a function of ambient temperature. Paper No. MC97-121. St. Joseph, Mich: ASAE.

Hungerford, L.L., Buhman, J.B., Dewell, R.D., Mader, T.L., Griffin, D., Smith, D.R., Nienaber, J.A., 2000. Investigation of heat stress mortality in four midwest feedlots. Int. Symp. on Veterinary Epidemiology and Economics. No. 616, 430-433. Breckenridge, Colorado.

Mader, T.L., Hungerford, L.L., Nienaber, J.A., Buhman, M.J., Davis, M.S., Hahn, G.L., Cerkoney, W.M., Holt, S.M., 2001. Heat stress mortality in midwest feedlots. J. Anim. Sci. $79[$ Suppl. 2]:2.

Pinheiro, J.C. and D.M. Bates. 2000. Mixed-Effects Models in S and S-PLUS. New York: Springer-Verlag. 
$\mathrm{R}$ version 2.1.1: free software at www.-project .org

Ratkowsky D.A. 1990. Handbook of Nonlinear Regression Models. New York: Marcel Dekker 
Table 1. Fixed Estimates and Residual Standard Error for Models Ignoring Experiment Treatment Factors

\begin{tabular}{|c|c|c|c|c|c|c|c|c|c|}
\hline & & & $\begin{array}{l}\text { LINEAR } \\
\text { EGRESSI } \\
\text { MODEL }\end{array}$ & & & & & $\begin{array}{l}\text { NONLINI } \\
\text { REGRESS } \\
\text { MODEI }\end{array}$ & \\
\hline 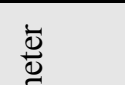 & $\begin{array}{l}\text { Lin } \\
\text { Fix }\end{array}$ & & $\begin{array}{r}\text { Quac } \\
\text { Fix }\end{array}$ & & $\begin{array}{l}\text { Quadrat } \\
\text { Random }\end{array}$ & $\begin{array}{l}\text { Mixed } \\
\text { tercept }\end{array}$ & $\frac{\bar{d}}{\tilde{U}}$ & $\begin{array}{r}\operatorname{Exp} \\
F \\
\end{array}$ & $\begin{array}{l}\text { ential } \\
\text { ed }\end{array}$ \\
\hline 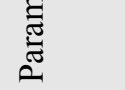 & Estimates & $\begin{array}{l}\text { Std } \\
\text { Error }\end{array}$ & Estimates & $\begin{array}{l}\text { Std } \\
\text { Error }\end{array}$ & Estimates & $\begin{array}{l}\text { Std } \\
\text { Error }\end{array}$ & हే & Estimates & Std Error \\
\hline Intercept & $-39.348 *$ & 2.9865 & 11.577 & 14.363 & 14.238 & 12.961 & Beta & $3.069 *$ & 0.0362 \\
\hline Temp & $4.712 *$ & 0.1053 & 0.924 & 1.050 & 0.759 & 0.946 & Kappa & $-0.509 *$ & 0.0010 \\
\hline Temp $^{2}$ & & & $0.068 *$ & 0.019 & $0.071 *$ & 0.017 & & & \\
\hline RSE & 26. & & 25 & & 22 & & RSE & & \\
\hline
\end{tabular}

* Estimate is significant, $\alpha=0.05$.

Table 2. Residual Standard Error, Information Criteria and Log Likelihood for Linear and Nonlinear Models

\begin{tabular}{|c|c|c|c|c|c|c|c|c|}
\hline \multirow{2}{*}{\multicolumn{2}{|c|}{ Model }} & \multirow{2}{*}{$\begin{array}{c}\text { Model } \\
\quad \#\end{array}$} & \multirow[t]{2}{*}{ Name } & \multirow[t]{2}{*}{ Random-effects } & \multirow[t]{2}{*}{ RSE } & \multicolumn{2}{|c|}{ Information Criteria } & \multirow{2}{*}{$\begin{array}{c}\text { Log- } \\
\text { Likelihood }\end{array}$} \\
\hline & & & & & & AIC & BIC & \\
\hline \multirow{10}{*}{ 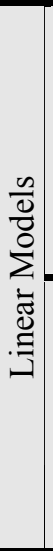 } & \multirow{5}{*}{ 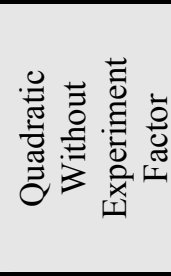 } & 1 & Fixed $\mathrm{lm}$ & None & 25.95 & 20948.31 & 20971.16 & -10470.16 \\
\hline & & 2 & Mixed lme & Intercept & 22.755 & 20580.85 & 20609.41 & -10285.42 \\
\hline & & 3 & Mixed Ime & Linear Temp & 22.357 & 20527.49 & 20567.47 & -10256.74 \\
\hline & & 4 & Mixed lme & QuadraticTemp & 22.364 & 20535.46 & 20592.59 & -10257.73 \\
\hline & & 5 & Mixed lme & $\begin{array}{l}\text { Diag } \\
\text { (Intercept,Temp,Temp }{ }^{2} \text { ) }\end{array}$ & 22.391 & 20529.73 & 20569.72 & -10257.87 \\
\hline & & 6 & Fixed lm-trt & None & 23.76 & 20649.22 & 20746.23 & -10307.61 \\
\hline & & 7 & Mixed lme-trt & Intercept & 21.689 & 20427.45 & 20530.16 & -10195.72 \\
\hline & & 8 & Mixed lme-trt & Linear Temp & 21.560 & 20411.51 & 20525.64 & -10185.75 \\
\hline & & 9 & Mixed lme-trt & QuadraticTemp & 21.563 & 20417.63 & 20548.89 & -10185.82 \\
\hline & & 10 & Mixed lme-trt & $\begin{array}{l}\text { Diag } \\
\text { (Intercept,Temp,Temp²) }\end{array}$ & 21.565 & 20412.01 & 20526.14 & -10186 \\
\hline \multirow{7}{*}{ 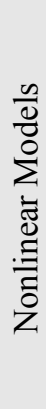 } & \multirow{4}{*}{ 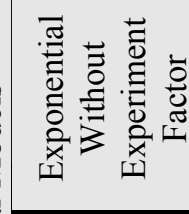 } & 11 & Fixed $\mathrm{nl}$ & None & 25.98 & 20942.83 & 20954.26 & -10469.42 \\
\hline & & 12 & Mixed nlme & beta & 22.475 & 20530.42 & 20553.27 & -10261.21 \\
\hline & & 13 & Mixed nlme & kappa & 22.542 & 20543.18 & 20566.03 & -10267.59 \\
\hline & & 14 & Mixed nlme & beta + kappa & 22.448 & 20534.27 & 20568.55 & -10261.13 \\
\hline & \multirow{3}{*}{ 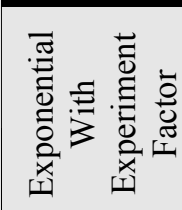 } & 15 & $\begin{array}{l}\text { Mixed } \\
\text { nlme-trt }\end{array}$ & beta & 21.667 & 20350.56 & 20453.41 & -10157.28 \\
\hline & & 16 & Mixed nlme-trt & kappa & 21.784 & 20368.92 & 20471.77 & -10166.46 \\
\hline & & 17 & Mixed nlme-trt & beta + kappa & 21.6 & 20350.96 & 20465.23 & -10155.48 \\
\hline
\end{tabular}


Table 3 Random Effects and Residual Standard Error for Linear Model Quadratic Regression and Nonlinear Models Exponential Regression

\begin{tabular}{|c|c|c|c|c|c|c|c|c|}
\hline \multirow{3}{*}{ Parameters } & \multicolumn{4}{|c|}{$\begin{array}{l}\text { Quadratic Regression Model without } \\
\text { Experiment Factors }\end{array}$} & \multicolumn{4}{|c|}{$\begin{array}{l}\text { Quadratic Regression Models } \\
\text { with Experiment Factors }\end{array}$} \\
\hline & $\begin{array}{c}\text { Mixed } \\
\text { lme } 2 \\
\text { Intercept }\end{array}$ & $\begin{array}{l}\text { Mixed } \\
\text { lme } 3 \\
\text { linear } \\
\text { Temp }\end{array}$ & $\begin{array}{c}\text { Mixed } \\
\text { lme } 4 \\
\text { Quadratic } \\
\text { Temp }\end{array}$ & $\begin{array}{l}\text { Mixed } \\
\text { lme } 5 \\
\text { Diag }\end{array}$ & $\begin{array}{c}\text { Mixed } \\
\text { lme-trt } 7 \\
\text { Intercept }\end{array}$ & $\begin{array}{c}\text { Mixed } \\
\text { lme-trt } 8 \\
\text { Linear } \\
\text { Temp }\end{array}$ & $\begin{array}{c}\text { Mixed } \\
\text { lme-trt } 9 \\
\text { Quadratic } \\
\text { Temp }\end{array}$ & $\begin{array}{c}\text { Mixed } \\
\text { lme-trt } 10 \\
\text { Diag }\end{array}$ \\
\hline & $\begin{array}{c}\text { Std } \\
\text { Dev }\end{array}$ & $\begin{array}{c}\text { Std } \\
\text { Dev }\end{array}$ & $\begin{array}{c}\text { Std } \\
\text { Dev }\end{array}$ & $\begin{array}{c}\text { Std } \\
\text { Dev }\end{array}$ & $\begin{array}{c}\text { Std } \\
\text { Dev }\end{array}$ & $\begin{array}{c}\text { Std } \\
\text { Dev }\end{array}$ & $\begin{array}{c}\text { Std } \\
\text { Dev }\end{array}$ & $\begin{array}{c}\text { Std } \\
\text { Dev }\end{array}$ \\
\hline Intercept & 12.21638 & 10.3375 & 3.7209 & 0.7603 & 9.90583 & 2.9843 & 2.50345 & 0.18186 \\
\hline Temp & - & 0.7607 & 0.4233 & 0.2486 & - & 0.4144 & 0.39958 & 0.33637 \\
\hline Temp $^{2}$ & - & - & 0.0122 & 0.0125 & - & - & 0.00084 & 0.00397 \\
\hline $\begin{array}{l}\text { Intercept \& } \\
\text { Temp }\end{array}$ & - & $-0.92^{c}$ & $-0.651^{c}$ & - & - & $-0.636^{c}$ & $-0.565^{c}$ & $\begin{array}{lll}- & - \\
\end{array}$ \\
\hline $\begin{array}{l}\text { Intercept \& } \\
\text { Temp }^{2}\end{array}$ & - & - & $-0.115^{\mathrm{c}}$ & - & - & - & $0.007^{\mathrm{c}}$ & - \\
\hline Temp \& Temp ${ }^{2}$ & - & - & $-0.128^{\mathrm{c}}$ & - & - & - & $-0.04^{\mathrm{c}}$ & - \\
\hline RSE & 22.755 & 22.357 & 22.364 & 22.391 & 21.68898 & 21.5604 & 21.5625 & 21.5648 \\
\hline
\end{tabular}

${ }^{\mathrm{c}}$ denotes correlation.

Table 4 Random Effects and Residual Standard Error for Nonlinear Models Exponential Regression

\begin{tabular}{|c|c|c|c|c|c|c|}
\hline \multirow{3}{*}{ Parameter } & \multicolumn{3}{|c|}{$\begin{array}{c}\text { Nonlinear Regression Models without } \\
\text { Experiment Factors }\end{array}$} & \multicolumn{3}{|c|}{$\begin{array}{l}\text { Nonlinear Regression Models with Experiment } \\
\text { Factors }\end{array}$} \\
\hline & $\begin{array}{c}\text { Mixed } \\
\text { nlme } 12 \\
\text { random } \\
\text { beta }\end{array}$ & $\begin{array}{c}\text { Mixed } \\
\text { nlme } 13 \\
\text { random } \\
\text { kappa }\end{array}$ & $\begin{array}{c}\text { Mixed } \\
\text { nlme } 14 \\
\text { random } \\
\text { both }\end{array}$ & $\begin{array}{c}\text { Mixed } \\
\text { nlme-trt } 15 \\
\text { random } \\
\text { beta }\end{array}$ & $\begin{array}{c}\text { Mixed } \\
\text { nlme-trt } 16 \\
\text { random } \\
\text { kappa }\end{array}$ & $\begin{array}{c}\text { Mixed } \\
\text { nlme-trt } 17 \\
\text { random } \\
\text { both }\end{array}$ \\
\hline & Std Dev & Std Dev & Std Dev & Std Dev & Std Dev & Std Dev \\
\hline Beta & 0.013369 & - & 0.14303 & 0.0103366 & - & 0.18466 \\
\hline Kappa & - & 0.00434 & 0.00225 & - & 0.00323 & 0.00346 \\
\hline Beta \& Kappa & - & - & $0.368^{\mathrm{c}}$ & - & - & $0.884^{\mathrm{c}}$ \\
\hline RSE & 22.47477 & 22.542 & 22.448 & 21.66688 & 21.7837 & 21.59978 \\
\hline
\end{tabular}

${ }^{\mathrm{c}}$ denotes correlation. 
Figure 1. Plot of Respiration Rate vs.

Ta with Linear Regression

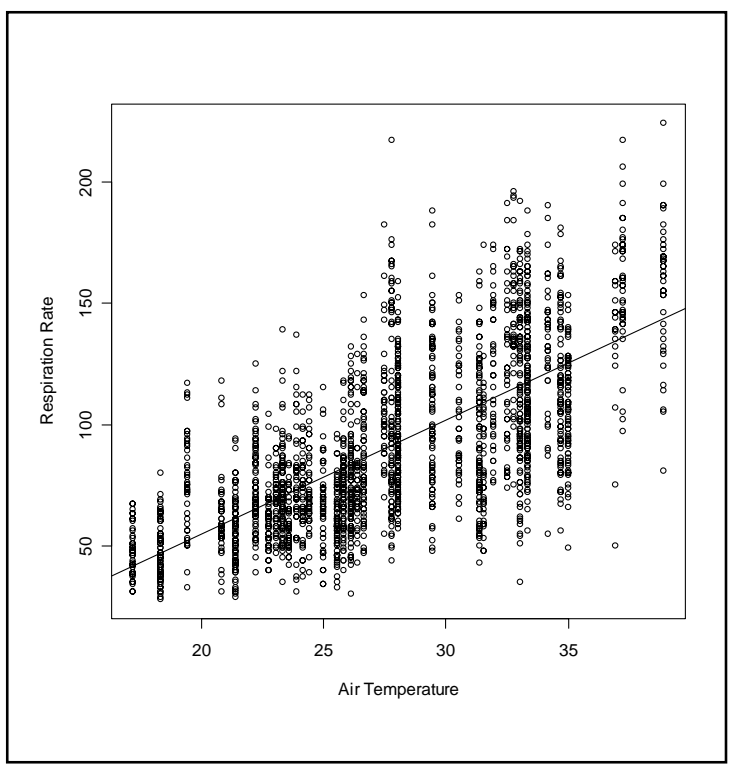

Figure 2. Linear Regression Lines for Each Genotype

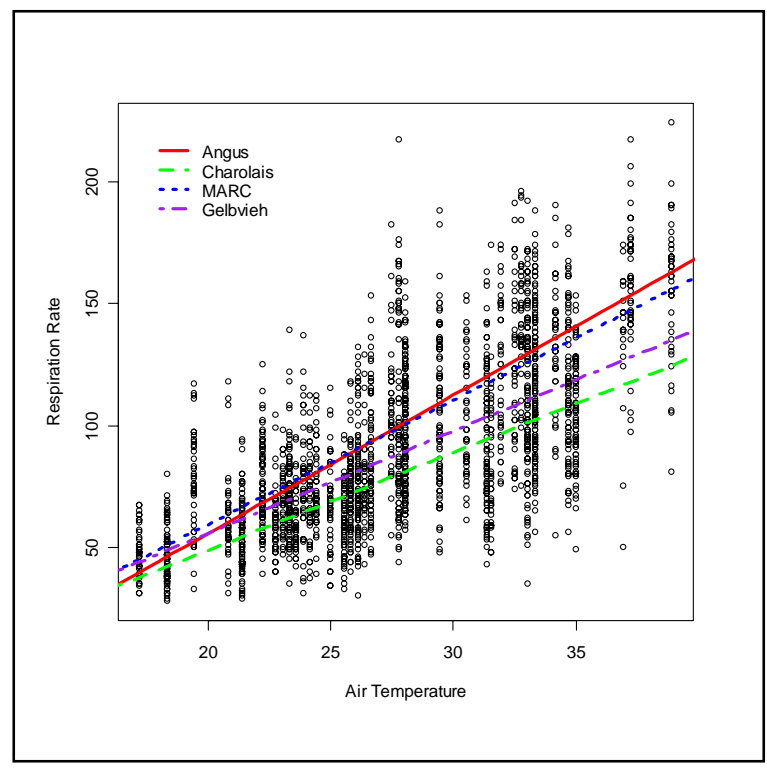

Figure 3. Individual Heifer 95\% Confidence Intervals for Fixed-effects Parameters

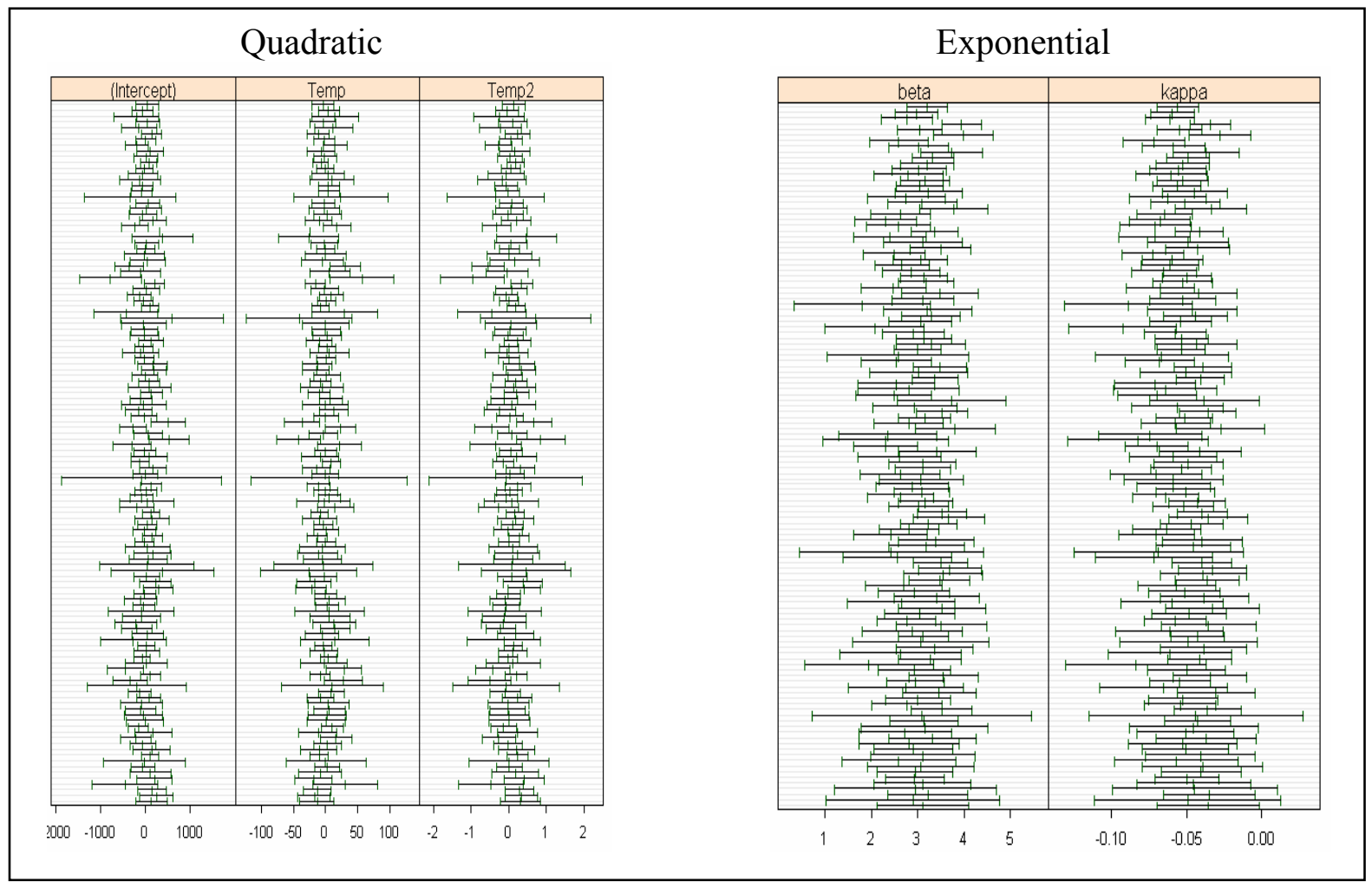


Figure 4. Scatter Plot of Correlation between Random Effects from Mixed Model Quadratic (random: linear Ta)

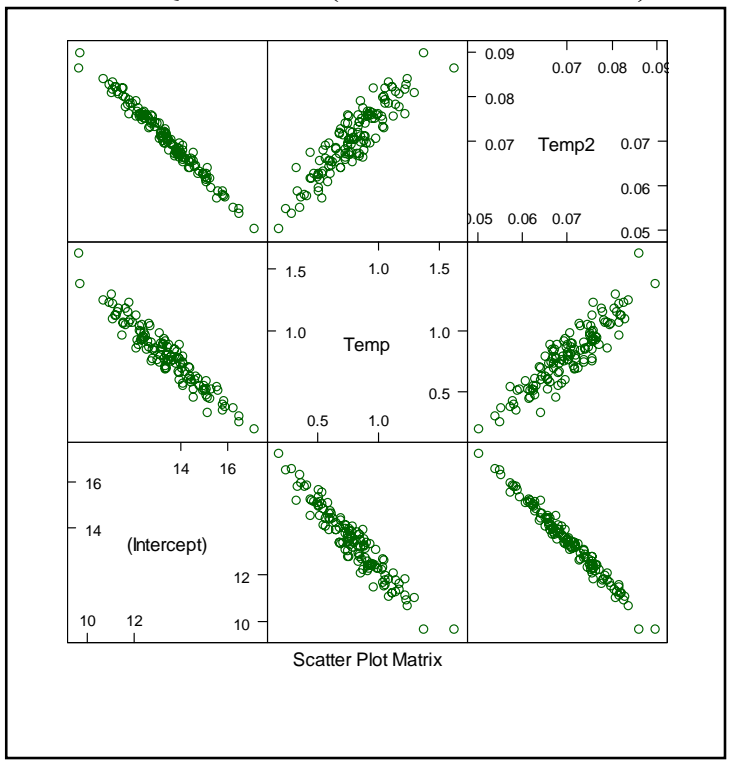

Figure 5. Individual and Mixed Model Fixed-effects:Quadratic(random: linear Ta)

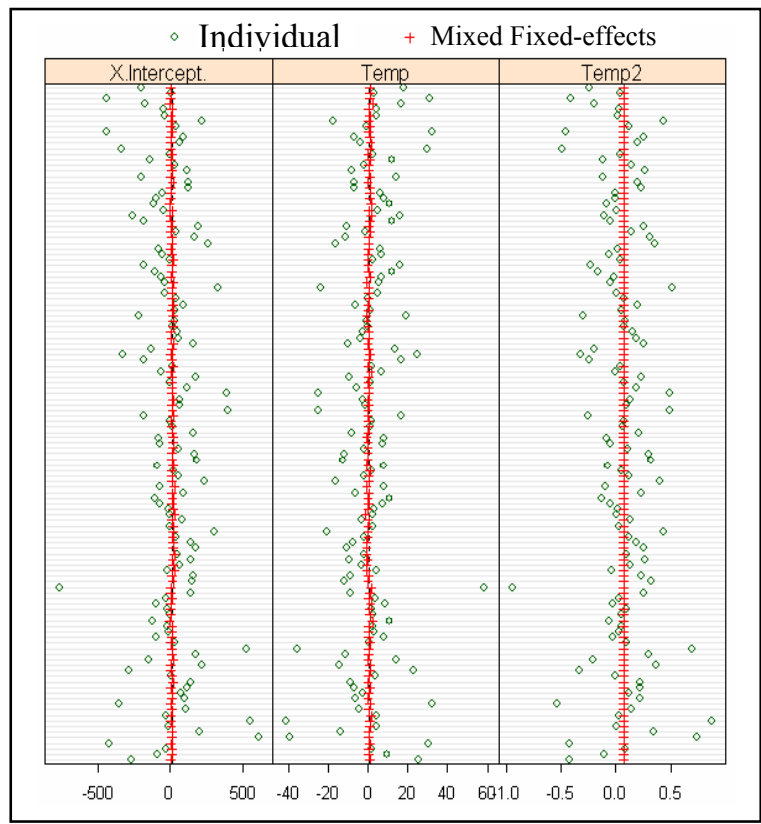

Figure 6 Predictions for population (fixed) and within-group (Individual Heifer) for observed RR (circles) versus Ta

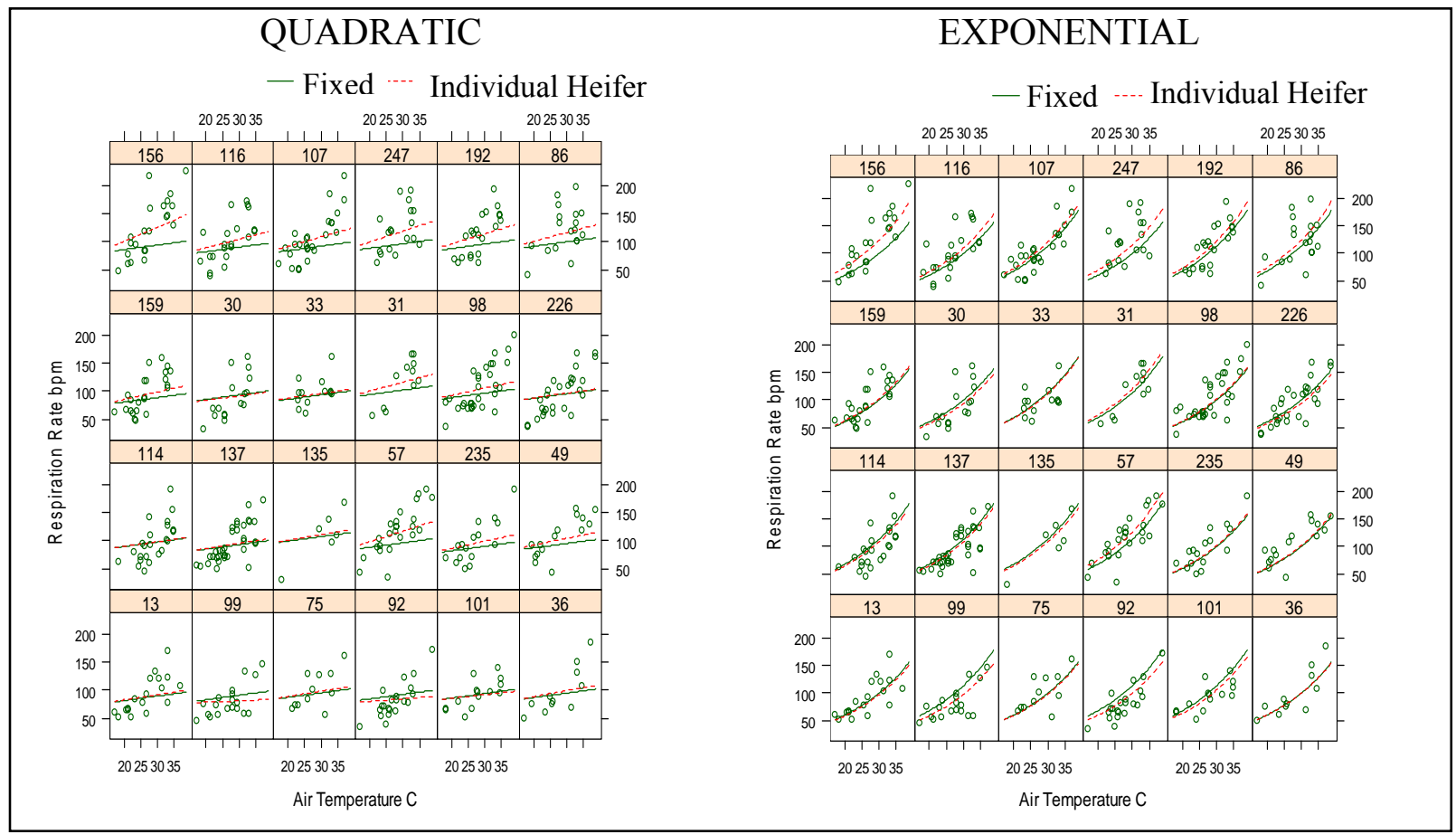


Figure 7. Parameter Estimates of Heifer Random Effects by Shade and Genotype from Mixed Model

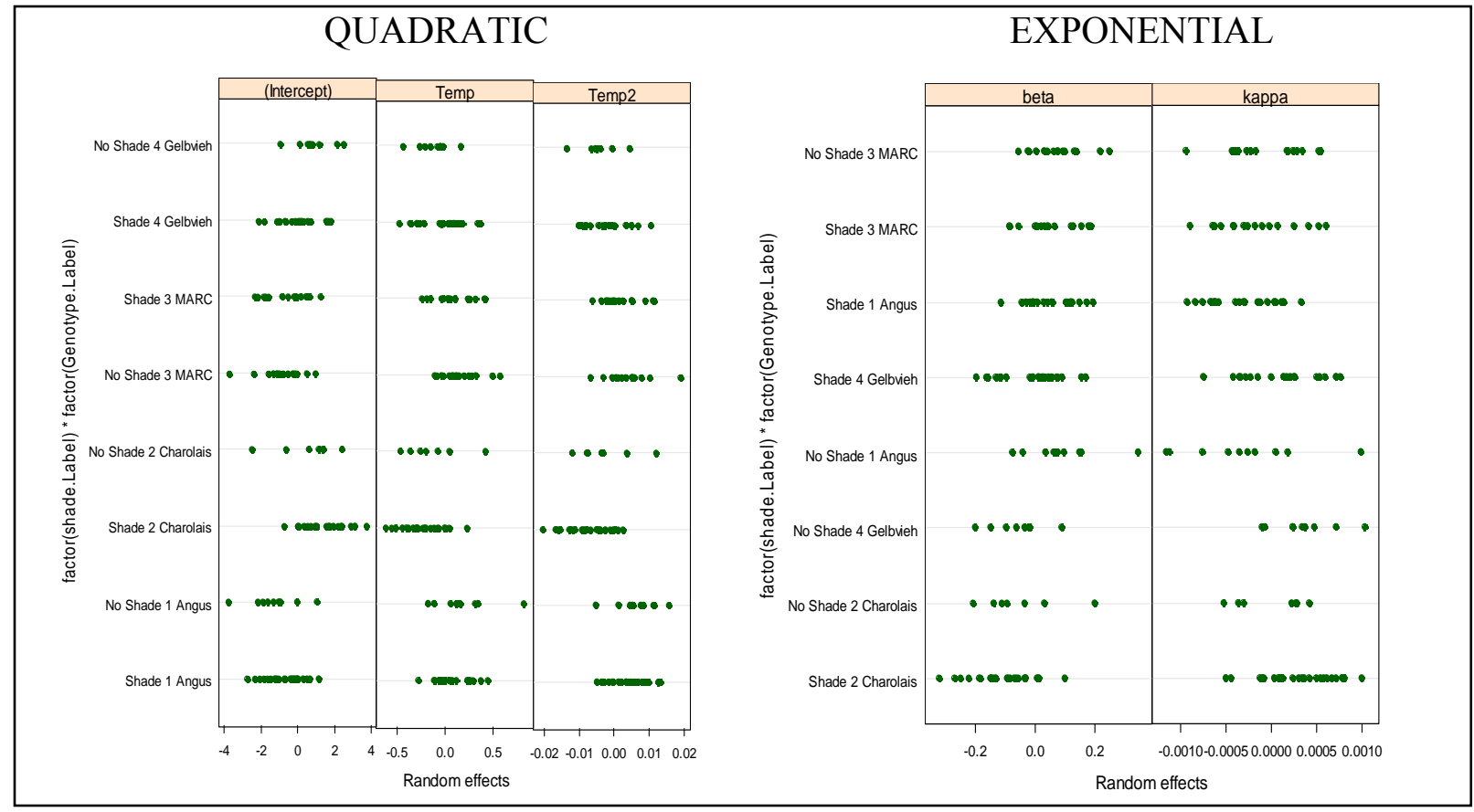

Figure 8. Box-plots of Standardized Residuals for Each Heifer Linear Mixed Model Quadratic (Random Linear)

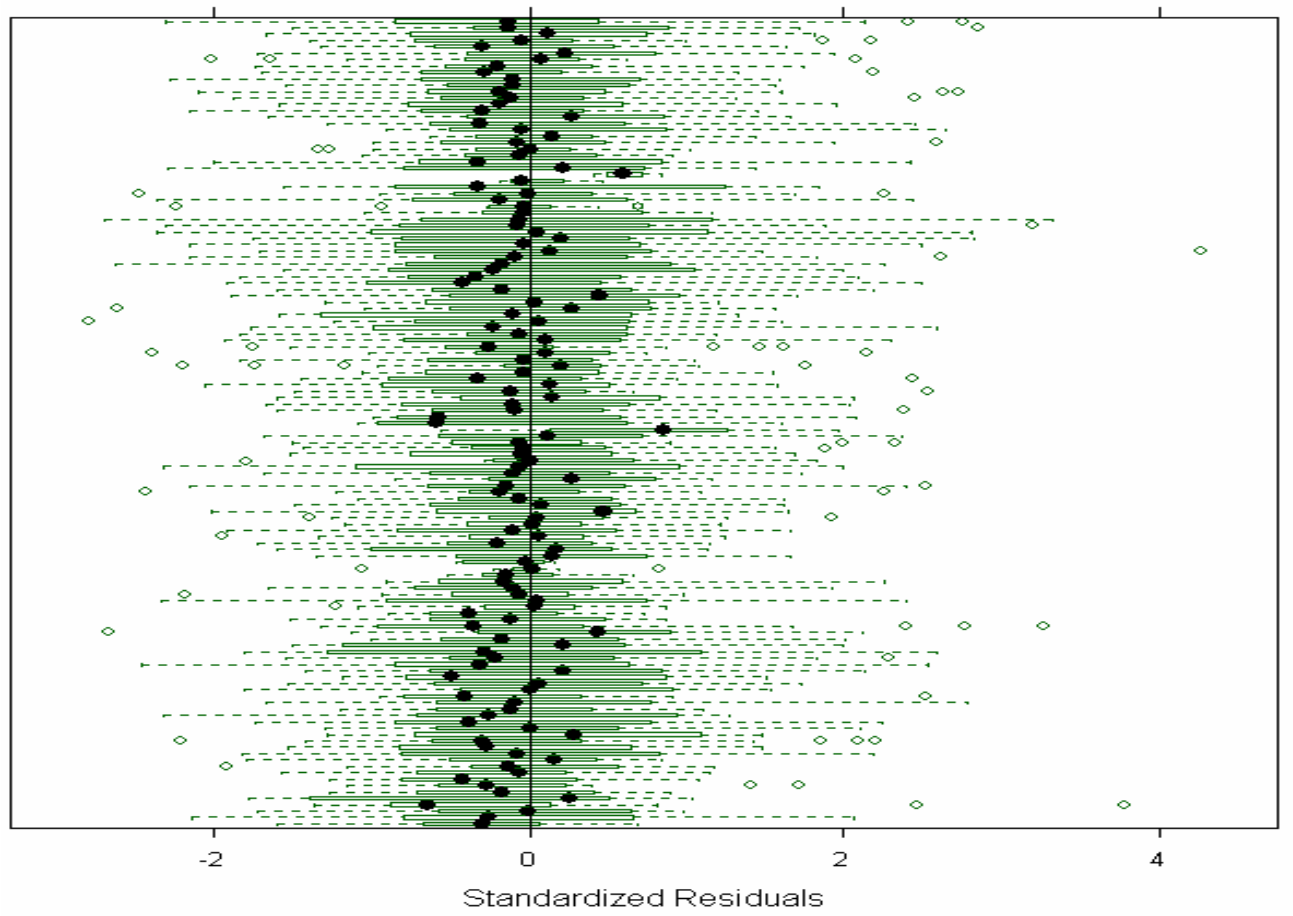


Figure 9. Plot of Standardized Residuals vs. Fitted Values by Shade and Genotype for Mixed Model

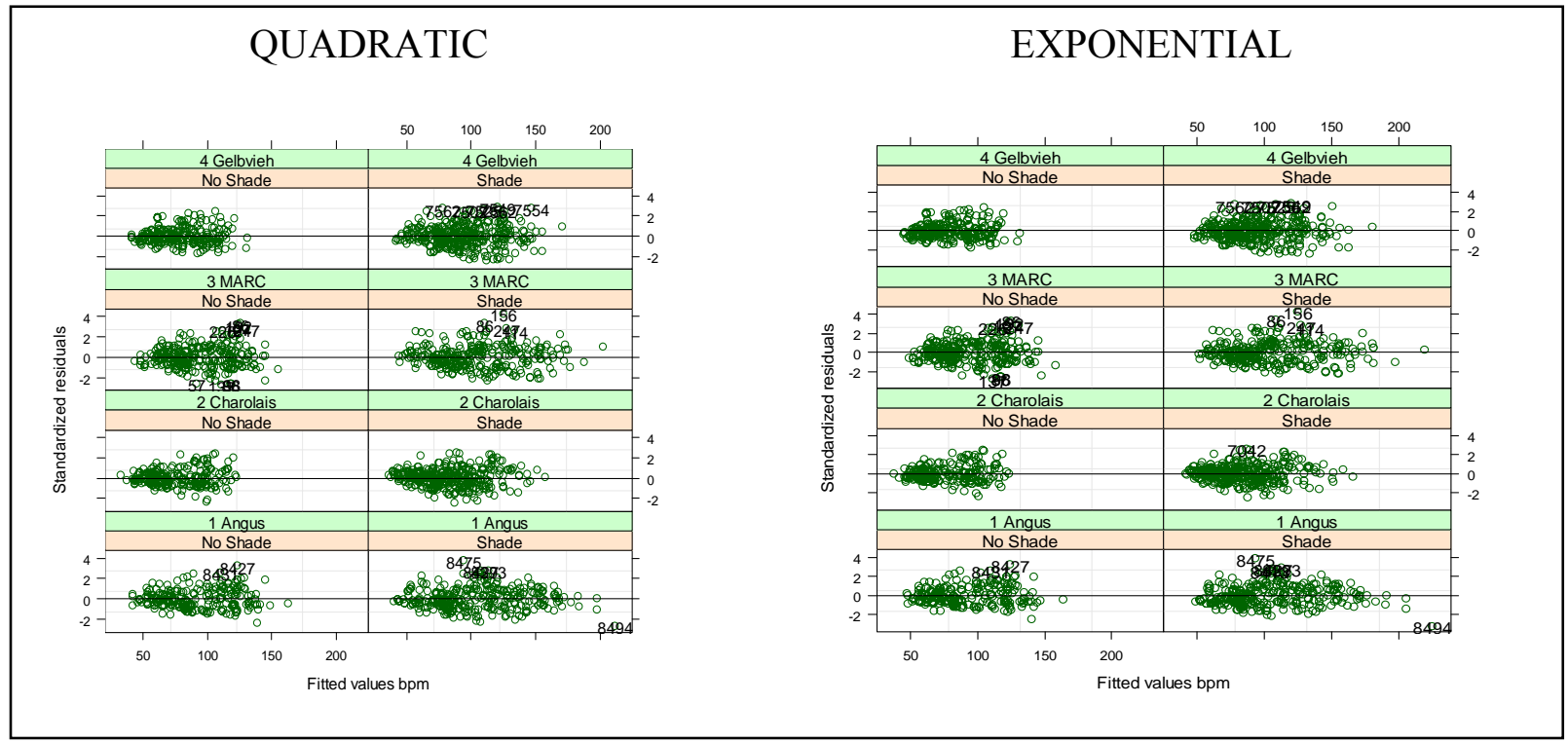

Fig 10. Normal Probability Plot of Standardized Residuals from Mixed Model Quadratic

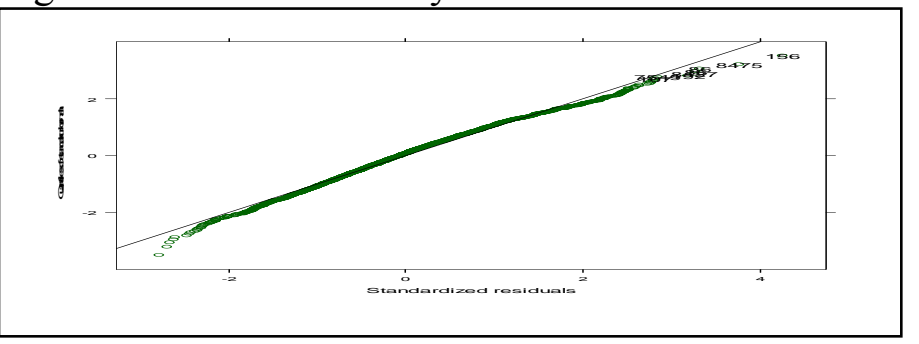

Figure 11. Normal Probability Plots of Residuals by Shade and Genotype from Mixed Model

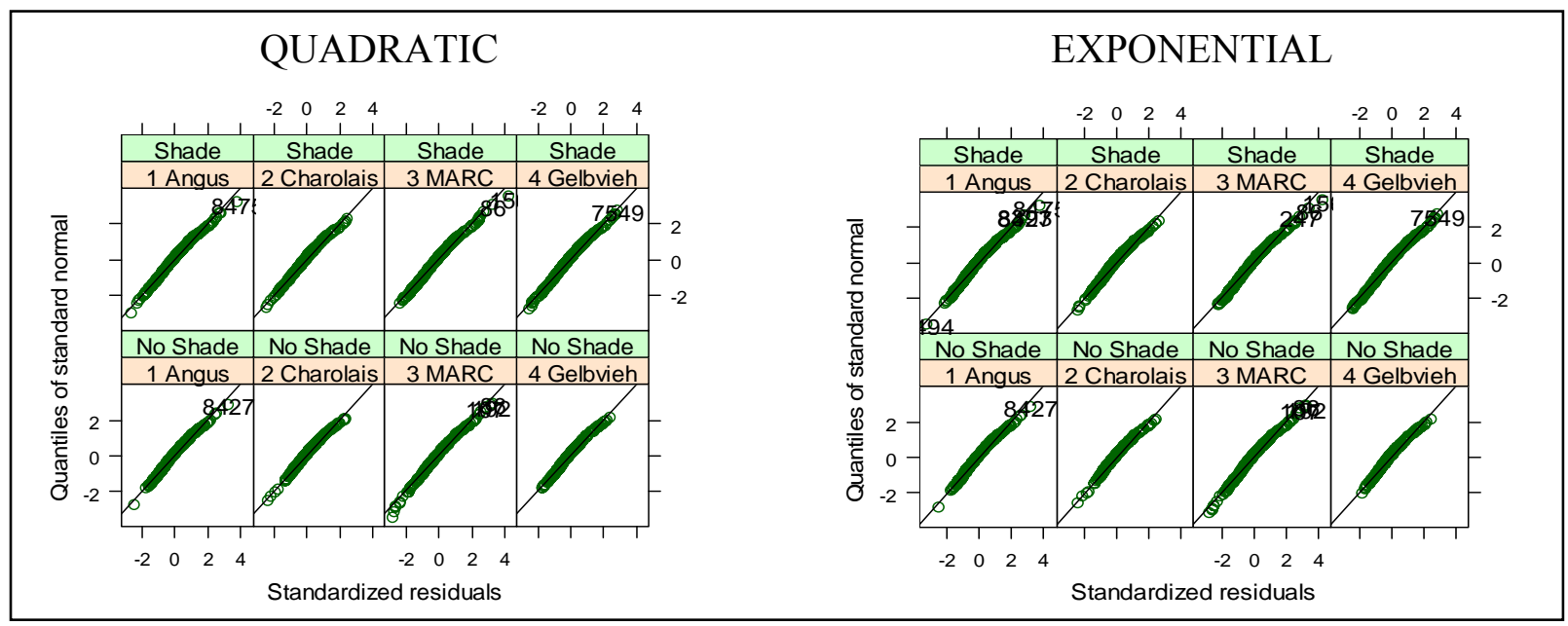

